\title{
Analysis of fracture mechanism for surrounding rock hole based on water-filled blasting
}

\author{
Jun Wang $^{1} \cdot$ Jingxuan Yang $^{1} \cdot{\text { Fengfeng } \mathrm{Wu}^{1}}^{1} \cdot$ Tengfei $\mathrm{Hu}^{1} \cdot$ Shams Al Faisal $^{1}$
}

Received: 28 August 2019/Revised: 28 November 2019/Accepted: 8 May 2020/Published online: 2 June 2020

(C) The Author(s) 2020

\begin{abstract}
The principles of fracture development during underwater blasting are examined based on explosion and impact dynamics, fluid dynamics, fracture dynamics, and field testing. The research reveals that the fracturing of the surrounding rock during underwater blasting is due to the combined action of shock and stress waves for the initial rock breakage and subsequent water expansion. The fracture development model for the surrounding rock of a drilling hole during underwater blasting is established. The rock fracturing range under the combined action of shock and stress waves is developed, as well as the fracture propagation rules after the wedging of the water medium into the fractures. Finally, the results of deep-hole underwater blasting tests on large rocks confirm the efficient utilization of explosive in the hole to improve the safety conditions. Accordingly, safe and static rock breaking under the detonation of high-effect explosive can be achieved. In addition, super-dynamic loading from the explosions and static loading from the water medium in the hole can be adequately combined for rock breaking.
\end{abstract}

Keywords Shock wave · Underwater blasting · Water wedge effect · Fracture development

\section{Introduction}

Traditional blasting technology consists of drilling and underwater blasting that uses a static water medium to replace the air medium in rock holes to enhance the wave impedance for explosive media. This reduces losses in the blasting energy, increases the utilization ratio of the limited explosive charge in the hole, reduces the explosive charge per unit volume in the hole, and enhances the explosive shock wave's rock breaking and guiding roles. Accordingly, underwater blasting technology contributes to maximizing the water wedge and fracturing actions in the hole, thereby expanding the fracturing range in the surrounding rock (Donze et al. 1997; Field and Pedersen 1971; Jang et al. 2018). Meanwhile, some potentially hazardous

Fengfeng Wu

wufengf@126.com

1 School of Mines, China University of Mining and Technology, Xuzhou 221116, Jiangsu, China conditions, including high temperatures, sparks, dust, and slungshots, can be effectively filtered and controlled via cooling and separation using a water medium in the hole, thereby improving the blasting environment and ensuring mine safety production (Yang 2015).

Greater in-depth knowledge of the damage rules for rocks under explosions is important for practical engineering applications (Kutter and Fairhurst 1971; Dai 2013; Li 2011). An abundance of rock blasting experimental data has been accumulated in previous studies, which provides qualitative or even some quantitative information for the damage mechanisms of explosions on rock. However, the complex rock mechanical behaviors under high strain rate dynamic loading suggest that the development of rock fractures under explosion-induced dynamic loads still requires further investigation ( $\mathrm{Li}$ et al. 2016; Yang et al. 2005).

Currently, rock breaking is the result of the combined actions of the shock wave with explosive detonation products. This is more aligned with actual rock fragmentation processes under blasting and is more widely accepted by many scholars 
(Dai 2013; Li 2011; Yang et al. 2005). This perspective suggests that the propagation velocity of high-intensity shock waves at the instant of detonation far exceeds the expansion velocity of the products considering the overall roles of the high-intensity shock wave and high-temperature high-pressure denotation products produced during the explosion in rock breaking processes. Moreover, the denotation wave first acts on the wall of the surrounding rock in the drilling hole and causes high-intensity rock shock waves, thereby producing compression failure on the surrounding rock. Next is the dissipation of the shock wave's rock breaking energy and the increased propagation distance. The shock wave decays gradually into a stress wave that acts on the surrounding rock outside the compressive damage region and produces tensile failure. This forms radial fractures in the holes. Finally, the denotation and expansion products enter the radial fractures in the surrounding rock and impose an air wedge action. This can further lead to the extension and expansion of radial fractures and increase the failure range of the surrounding rock (Yang et al. 2018).

During the rock breaking process, the shock wave produced from the explosive in the hole and the high-temperature high-pressure detonation products expand isotopically in the original charging space. This can instantaneously heat the surrounding media of the explosive and cause secondary damage via expansion extrusion. After the first rock breaks from the shock wave, the surrounding rock can become discontinuous and anisotropically complex rock structures consisting of multiple fractures and failure planes. Using traditional mechanical methods for continuous rock media will inevitably lead to errors in the analysis of the failure mechanism for the surrounding rock. Since its introduction in rock mechanics, fracture mechanics has developed gradually into rock fracture mechanics, which focuses on analyzing dynamic rock fractures after long-term development (Yang 2015; Dai 2013). Previous research has analyzed the results of rock fracture development and extension features. Rock fracturing mechanisms based on fracture mechanics illustrate and evaluate the instability and damage of complex rock structures (Li et al. 2005; Yang et al. 2014; Zuo et al. 2019). Therefore, the present study considers the development rules for fractures produced in water-expansioninduced rock breaking processes in drilling holes from the perspective of fracture mechanics. This provides insightful guidance for the application of underwater drilling and blasting.

\section{Rock breaking in underwater blasting}

During underwater blasting processes, the failure mechanisms of the surrounding rock exhibit nearly the same destruction process and zoning characteristics compared with ordinary charging blasting (Yang 2015). In other words, after the detonation in drilling, the detonation wave first acts on the water medium around the explosive, and the excited shock wave then strikes the wall of the surrounding rock wall through the thin water medium and crushes it near the hole. During the propagation process, the shock wave decays gradually into a stress wave and imposes tensile failures on the surrounding rock, thereby producing certain radial and circular fractures at some distance from the blasting holes (Li 2011; Yang et al. 2018). Because the water medium in the hole has poor compressibility and exhibits a favorable explosion transfer performance, the explosive detonation in the hole can produce more-uniform and wider damage to the surrounding rock (Huang and $\mathrm{Li}$ 2015). Figure 1 shows the rock breakage and different zones for underwater blasting conditions.

The shock wave in the water medium around the explosive first strikes the drilling hole wall. The intensity of the excited rock shock wave far exceeds the rock's dynamic compressive strength, which can produce initial strong compression failure in the surrounding rock (Zhang 1990; He and Jun 2019). The impact of the high-intensity shock wave crushes the hard rock and forms compacted cavities in the soft rock (Yang and Ding 2018). Overall, the initial high-intensity shock wave formed during the explosive detonation in the hole first forms compactions with the radius of the compaction or crushed zone in the surrounding rock $r_{\mathrm{c}}$.

As the wave propagation distance increases, the highintensity shock wave decays gradually into a low-intensity stress wave. The surrounding rock of the drilling hole is compressed along the radial direction, leading to tensile deformation of the surrounding rock along the tangential direction. Rock generally has a low tensile strength that is approximately $0.02-0.10$ times the compressive strength (Dai 2013). When the tangential stress in the surrounding rock reaches the ultimate tensile strength, the surrounding

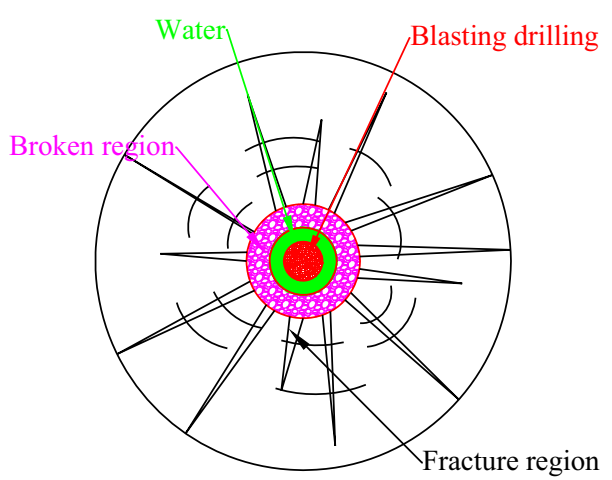

Fig. 1 Fracture development and partitioning during underwater blasting processes 
rock breaks along the tangential direction and forms radial fractures connected with the compactions or crushed zones. The formation of radial fractures around the hole further weakens the stress wave in the surrounding rock and immediately releases the original compressive deformation energy accumulated within the surrounding rock in the hole cavity. Meanwhile, tensile stress in the radial direction to the stress wave is formed in the rock, which results in antiradial motion and forms circular tensile fractures. It is observed that the stress wave in the surrounding rock causes both radial and circular fractures that expand and are gradually connected. This finally forms a fracture zone with a tensile failure radius of the surrounding rock of the drilling hole $r_{\mathrm{t}}$.

The high-intensity shock wave causes the surrounding rock in the hole to exhibit rheological characteristics, suggesting the rock medium can be regarded as a fluid. Underwater blasting in rock holes indicates plane strain conditions, and the triggered stress at any a point in the surrounding rock under the high-intensity shock wave at the drilling hole wall can be represented as (Dai 2001; Yang et al. 2018).

$\left.\begin{array}{l}\sigma_{r}=p_{\mathrm{c}}\left(r / r_{\mathrm{b}}\right)^{-\alpha}, \sigma_{\varphi}=-\lambda \sigma_{r} \\ \sigma_{z}=\mu_{\mathrm{d}}\left(\sigma_{r}+\sigma_{\varphi}\right)\end{array}\right\}$

where

$\alpha=2+\frac{\mu_{\mathrm{d}}}{1-\mu_{\mathrm{d}}}, \lambda=\frac{\mu_{\mathrm{d}}}{1-\mu_{\mathrm{d}}}$

In Eqs. (1) and (2), $\sigma_{r}$ is the radial stress of the surrounding rock; $\sigma_{\varphi}$ and $\sigma_{z}$ are the tangential stress and axial stress, respectively; $p_{\mathrm{c}}$ is the initial pressure of the shock wave on the wall of the drilling hole; $r_{\mathrm{b}}$ is the radius of the drilling hole; $\alpha$ is the attenuation coefficient of the shock wave; $\lambda$ is the lateral confining pressure coefficient; and $\mu_{\mathrm{d}}$ is the dynamic Poisson's ratio of the surrounding rock (generally, $\mu_{\mathrm{d}}=0.8 \mu$ (Dai 2013), where $\mu$ is the static Poisson's ratio).

The surrounding rock in a drilling hole is smashed when the high-pressure shock wave in the water medium acts directly on the wall. Meanwhile, the radius of the compaction or crushed zone in the surrounding rock from the shock wave can be calculated as (Zhang 1990; Dai 2001).

$r_{\mathrm{c}}=\left(\frac{\sqrt{2} \sigma_{\mathrm{c}} \xi^{1 / 3}}{C p_{\mathrm{c}}}\right)^{-\frac{1}{\alpha}} r_{\mathrm{b}}$

where $C=\left[(1+\lambda)^{2}-2 \mu_{\mathrm{d}}\left(1-\mu_{\mathrm{d}}\right)(1-\lambda)^{2}+\lambda^{2}+1\right]^{\frac{1}{2}} \sigma_{\mathrm{c}}$ is the rock's uniaxial compressive strength, $C$ is an intermediate variable, and $\xi$ is the loading strain rate of the surrounding rock. Generally, $\xi$ is high in the crushed zone of the surrounding rock $\left(10^{2}-10^{4} \mathrm{~s}^{-1}\right)$ but is lower outside this zone $\left(1-10^{3} \mathrm{~s}^{-1}\right)(\mathrm{Li} 2011)$.
As the shock wave propagates in the surrounding rock, it decays gradually into a stress wave and continues imposing tensile failure on the surrounding rock. The radius of the crushed zone in the surrounding rock can be calculated as (Yang 2015; Dai 2013).

$r_{\mathrm{t}}=\left(\frac{\sigma_{\mathrm{t}}}{\sigma_{\mathrm{c}} \xi^{1 / 3}}\right)^{-\frac{1}{\beta}}\left(\frac{\sqrt{2} \sigma_{\mathrm{c}} \xi^{1 / 3}}{C p_{\mathrm{c}}}\right)^{-\frac{1}{\alpha}} r_{\mathrm{b}}, \beta=2-\frac{\mu_{\mathrm{d}}}{1-\mu_{\mathrm{d}}}$

where $r_{\mathrm{t}}$ is the tensile failure radius of the surrounding rock of the drilling hole, $\sigma_{\mathrm{t}}$ is the rock's uniaxial tensile strength, and $\beta$ is the attenuation coefficient of the stress wave.

Combining Eqs. (3) and (4) gives the thickness of the crushed zone in the surrounding rock of the drilling hole, denoted as $D_{\mathrm{t}}$, which is calculated as

$D_{\mathrm{t}}=\left[\left(\frac{\sigma_{\mathrm{t}}}{\sigma_{\mathrm{c}} \xi^{1 / 3}}\right)^{-\frac{1}{\beta}}-1\right]\left(\frac{\sqrt{2} \sigma_{\mathrm{c}} \xi^{1 / 3}}{C p_{\mathrm{c}}}\right)^{-\frac{1}{\alpha}} r_{\mathrm{b}}$

Given the rock's mechanical parameters, the length of the crushed zone in the surrounding rock of the drilling hole during underwater blasting can be acquired only by substituting the related parameters into Eqs. (3) and (4). For convenient analyses, only some common physical and mechanical parameters of typical rocks are listed in Table 1.

The intensity of the rock transmission shock wave with a water medium in the drilling hole is approximately 2.75 GPa (Yang 2015). Substituting the mechanical parameters listed in Table 1 into Eq. (4) provides the radii of the crushed zones in the surrounding rock with different lithological properties, as given in Table 2.

As listed in Table 2, the radius of the crushed zone in the surrounding rock induced from the explosion in the hole under different lithological conditions is overall 10-15 times greater than the drilling radius.

\section{Static pressure fracturing mechanism}

When performing underwater blasting on coal rocks, the explosive load acts uniformly on the hole wall after detonation because of the water medium. This can lead to the appearance of significant uniform and symmetric fractures.

Table 1 Physical and mechanical parameters of common rocks (Dai 2013)

\begin{tabular}{lllll}
\hline Parameter & Shale & Sandstone & Limestone & Granite \\
\hline$\sigma_{\mathrm{c}}(\mathrm{MPa})$ & 55 & 80 & 140 & 175 \\
$\sigma_{\mathrm{t}}(\mathrm{MPa})$ & 16.5 & 24.0 & 25.0 & 32.0 \\
$\mu$ & 0.31 & 0.25 & 0.26 & 0.22 \\
$\mu_{\mathrm{d}}$ & 0.25 & 0.20 & 0.21 & 0.18 \\
\hline
\end{tabular}


The combined shock and stress waves form a series of fractures in the surrounding rock. During the subsequent expansion processes from the explosive detonation products, the expansion products aid the water in the hole to wedge into the fractures at high speeds, which impact the fracture surface and accelerate their development around the hole. The research results of Loeber and Sih (Loeber and Sih 1968; Sih and Loeber 1969; Yang et al. 2016; Liu et al. 2019; Gao et al. 2008) show that these fractures can develop uniformly under a uniform pressure.

The subsequent expansion of the detonation products in the hole helps the water medium to extrude and enter the fractures of the surrounding rock, which further accelerates the fracture development. Based on the maximum circumferential crack arrest criterion proposed by Erdogan and Sih, the stress on the tip of a type-I or type-II fracture around the drilling hole in polar coordinates can be expressed as (Dai 2013; Gao et al. 2008).

$\sigma_{k \theta \theta}=\frac{1}{4 \sqrt{2 \pi r}}\left[\left(3 \cos \frac{\theta}{2}+\cos \frac{3 \theta}{2}\right) K_{\mathrm{I}}-3\left(\sin \frac{\theta}{2}+\sin \frac{3 \theta}{2}\right) K_{\mathrm{II}}\right]$

where $\sigma_{k \theta \theta}$ is the tangential stress on the composite fracture, $\theta$ is the polar angle of the fracture tip, and $K_{\mathrm{I}}$ and $K_{\mathrm{II}}$ are the dynamic stress intensity factors of type-I and type-II fractures, respectively.

According to the maximum circumferential stress criterion for the fracture initiation in the surrounding rock, the maximum tangential stress on the fracture tip is when

$\left.\frac{\partial \sigma_{k \theta \theta}}{\partial \theta}\right|_{\theta_{0}}=0,\left.\frac{\partial^{2} \sigma_{k \theta \theta}}{\partial \theta^{2}}\right|_{\theta_{0}}<0$

where $\theta_{0}$ is the critical fracture initiation angle. Accordingly, the optimal value of $\theta_{0}$ for the surrounding rock should satisfy

$\left(\sin \frac{\theta_{0}}{2}+\sin \frac{3 \theta_{0}}{2}\right) K_{\mathrm{I}}+\left(\cos \frac{\theta_{0}}{2}+3 \cos \frac{3 \theta_{0}}{2}\right) K_{\mathrm{II}}=0$

Combining Eqs. (6) and (8) describes the maximum circumferential stress along the optimal fracture initiation direction. This provides the fracture initiation condition in the surrounding rock as

$\sigma_{\theta \mathrm{cri}}=K_{\mathrm{Ic}} / \sqrt{2 \pi r_{0}}$

where $\sigma_{\theta \text { cri }}$ is the critical circumferential stress at the moment of fracture initiation, $K_{\mathrm{Ic}}$ is the rock's fracture toughness during the development of the type-I fracture, and $r_{0}$ is the initial fracture length. Thus, the fracture initiation criterion for type-I and type-II fractures during underwater blasting can be described as
Table 2 Radii of crushed zones in surrounding rock

\begin{tabular}{lllll}
\hline Parameter & Shale & Sandstone & Limestone & Granite \\
\hline$\alpha$ & 2.33 & 2.25 & 2.27 & 2.22 \\
$\beta$ & 1.67 & 1.75 & 1.73 & 1.78 \\
$\lambda$ & 0.33 & 0.25 & 0.27 & 0.22 \\
$C$ & 1.75 & 1.67 & 1.69 & 1.65 \\
$r_{\mathrm{t}}(\mathrm{m})$ & 0.59 & 0.47 & 0.50 & 0.43 \\
\hline
\end{tabular}

$$
\left(3 \cos \frac{\theta_{0}}{2}+\cos \frac{3 \theta_{0}}{2}\right) K_{\mathrm{I}}-3\left(\sin \frac{\theta_{0}}{2}+\sin \frac{3 \theta_{0}}{2}\right) K_{\mathrm{II}}=4 K_{\mathrm{Ic}}
$$

The uniform load transference from the water medium allows the detonation load to act uniformly on the wall of the drilling hole along the radial direction. Thus, few typeII fractures are produced around the drilling hole. Therefore, this blasting condition suggests that the formation and development of type-II fractures in the surrounding rock should not be considered. Equation (8) suggests that the fracture initiation angle of type-I fractures is zero, and the fractures continue to develop along the extension direction of the fracture tip.

Considering the difficulty in acquiring the rock's fracture toughness, some scholars have attempted to establish the relationship between the rock's fracture toughness and the uniaxial tensile strength (Dai 2013; Zhang 2002). Researchers from the Yangtze Hydroelectrical Institute conducted related tests and found that $K_{\mathrm{Ic}}=0.141 \sigma_{\mathrm{t}}^{1.15}$, which facilitates estimations of the fracture toughness of rocks with different lithological properties.

After the formation of radial fractures around the drilling hole, the water medium is driven by the high-temperature high-pressure detonation products before wedging into fractures of the surrounding rock at high speeds (Sun et al. 2018). This applies uniform pressure on the fractures and accelerates their development. With the increased fracture length in the surrounding rock, the fractures in the drilling hole expand gradually. The pressure of the detonation gas in the fractures drops gradually, and the fracture development velocity reduces steadily until the fractures in the surrounding rock stop developing. The transference of the uniform load from the water medium causes symmetric expansion of the fractures in the surrounding rock due to the cylindrical explosive. Next, by analyzing the development behavior of a fracture as a function of depth, the fracture development model under wedging conditions can be established, as illustrated in Fig. 2.

As the development length for a single fracture increases, the pressure of the water medium within the fractures reduces. The final fracture development length from the 
water medium is denoted as $l_{\mathrm{w}}$, and the termination pressure corresponding to the stopped fracture development is denoted as $p_{\mathrm{w}}$. Because the angle between the fracture tip and the wall in the surrounding rock far from the drilling hole is sufficiently small to be approximated as zero, the extension lengths of the fractures in the surrounding rock can be described as

$$
\left.\begin{array}{rl}
p_{\mathrm{w}} & =\frac{K_{\mathrm{Ic}}}{\sqrt{2 \pi l_{\mathrm{w}}}}, u_{\mathrm{t}}=\frac{K_{\mathrm{Ic}}}{2 G} \sqrt{\frac{l_{\mathrm{w}}}{2 \pi}}(k+1) \\
\frac{p_{\mathrm{c} 1}}{p_{\mathrm{w}}} & =\left[1+\frac{n_{\mathrm{c}} u_{\mathrm{t}}\left(2 D_{\mathrm{t}}+l_{\mathrm{w}}\right)}{\pi r_{\mathrm{c}}^{2}}\right]^{k}
\end{array}\right\}
$$

where $n_{\mathrm{c}}$ is the total number of fractures around the drilling hole, $u_{\mathrm{t}}$ is the half-width of the fracture root, $l_{\mathrm{w}}$ is the fracture extension length, $G$ is the shear modulus, $p_{\mathrm{w}}$ is the termination pressure when the fractures stop developing, $p_{\mathrm{c} 1}$ is the water pressure in the crushed zone of the surrounding rock, and $k$ is the adiabatic exponent of the explosive.

Eliminating $p_{\mathrm{w}}$ and $u_{\mathrm{t}}$ allows the implicit function of the extension length of the fracture in the surrounding rock to be given as

$\left(\frac{p_{\mathrm{c} 1} \sqrt{2 \pi l_{\mathrm{w}}}}{K_{\mathrm{Ic}}}\right)^{\frac{1}{k}}-\frac{n_{\mathrm{c}} K_{\mathrm{Ic}} \sqrt{l_{\mathrm{w}}}(k+1)\left(2 D_{\mathrm{t}}+l_{\mathrm{w}}\right)}{2 \sqrt{2 \pi} G \pi r_{\mathrm{c}}^{2}}=1$

For example, sandy surrounding rock has a tensile strength of $24 \mathrm{MPa}$, a Poisson's ratio of 0.25 , and an elastic modulus of $41 \mathrm{GPa}$ (Yang 2015). After substituting these parameters into Eq. (12), the development characteristics of fractures with diameters of $45 \mathrm{~mm}$ are acquired as shown in Fig. 4 (Liu et al. 2017).

As shown in Fig. 3, a higher initial expansion pressure of the water medium in the hole is required for fracture initiation in the surrounding rock with more fractures. Given the number of produced fractures in the surrounding rock, the termination fracture extension length increases with the initial expansion pressure of the water medium in the hole. Furthermore, the greater the number of fractures around the drilling hole, the smaller the change in the

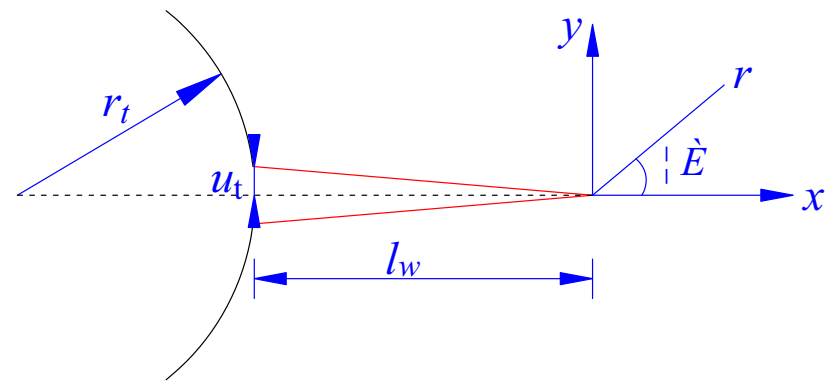

Fig. 2 Fracture development model with underwater blasting

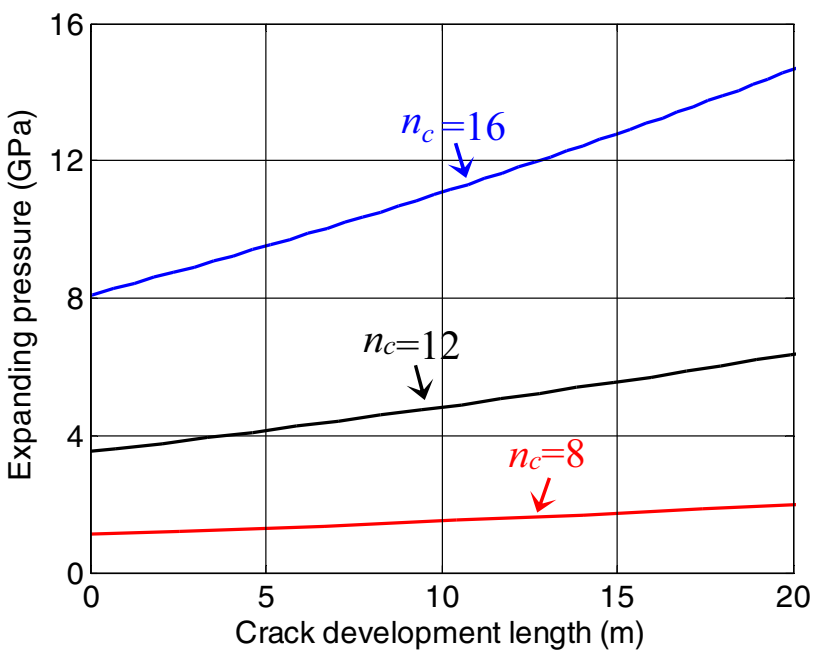

Fig. 3 The development characteristics of fractures with diameters of $45 \mathrm{~mm}$

initial expansion pressure of the water medium. These results are apparent from the perspective of energy conservation. Within the smaller fracture space, the fractures have a greater extension kinetic energy; therefore, they expand at greater velocities. In contrast, a single fracture has a lower extension kinetic energy with a smaller fracture extension velocity in the surrounding rock, which has more fractures. Similarly, under the same initial expansion pressure of the water medium, the fracture extension termination length is greater in the surrounding rock with fewer fractures (Cheng 2019).

It is concluded that the adoption of relevant technical measures achieves directional extension of fractures among holes. Restricting the formation of fractures along nondominant directions can significantly enhance the extension of the water medium into the fractures of the surrounding rock. This prolongs the termination fracture extension length and achieves a directed conducting performance in the surrounding rock at a large hole spacing. Accordingly, both the drilling operation and costs can be reduced.

\section{Test analysis of underwater blasting}

The LS-DYNA program is a full-featured nonlinear program to model geometric, material, and contact properties of a drilling hole, which is based primarily on the lagrange algorithm, explicit solution, and nonlinear dynamic analysis (Xie 2002). It has good applicability for the dynamic failure simulation of rocks under high strain rate blasting. Strong shock waves are generated at the instant of explosion and destroy the surrounding objects. The LS-DYNA can provide a model for high-energy explosive along with 
various explosive state equations to simulate the entire shock wave propagation process and the structural transient response.

The present study also involved simulations of the blasting-induced rock fracturing process when the drilling hole is full of water. The rock explosive is described using the state equation as (Guo et al. 2016)

$P=A\left(1-\frac{W}{R_{1} V}\right) e^{-R_{1} V}+B\left(1-\frac{W}{R_{2} V}\right) e^{-R_{2} V}+\frac{\omega E}{V}$

where $P$ is the detonation pressure, $V$ is the relative volume, $E$ is the internal energy per unit volume, and $\omega, A, B$, $R_{1}$, and $R_{2}$ are the material constants. Table 3 details the explosive parameters for rock explosive.

The state equation for the water can be described using the following linear polynomial:

$P=\sum_{i=0}^{2} C_{i} \mu^{i}+E \sum_{i=4}^{6} C_{i} \mu^{i-4}$

where $\mu=\frac{1}{V}-1$. This linear polynomial can be used to describe the water with $C_{4}=C_{5}=0.4$ and all other parameters equal to zero. Additionally, the density of water is $1000 \mathrm{~kg} / \mathrm{m}^{3}$ and the initial relative volume $V_{0}$ is set to 1.0. The LS-DYNA finite-element model was established by applying fixed and non-reflecting boundary conditions on the surrounding media, as shown in Fig. 4.

The established model shown in Fig. 4 has a size of $3000 \mathrm{~mm} \times 3000 \mathrm{~mm} \times 4000 \mathrm{~mm}$. The ammonium nitrate explosive is charged and uncoupled with a diameter of $22 \mathrm{~mm}$, while the diameter of the blasting hole is $40 \mathrm{~mm}$. The fluid-solid coupled calculation method was applied, in which (1) the Lagrangian algorithm was used for the surrounding rock and the blocking segment and (2) the ALE algorithm was used for the coupling between the explosive and the water. Figure 6 shows the effective stress based on the fluid-solid coupling model when the hole was full of water.

As shown in Fig. 5, the detonation wave was excited as the detonation first acted on the water medium layer around the explosive during the fluid-solid coupling blasting

Table 3 Parameters of explosive

\begin{tabular}{llll}
\hline Parameter & Value & Parameter & Value \\
\hline$\rho\left(\mathrm{kg} / \mathrm{m}^{3}\right)$ & 1100 & $R_{1}$ & 5.15 \\
$D(\mathrm{~m} / \mathrm{s})$ & 5900 & $R_{2}$ & 0.90 \\
$P(\mathrm{GPa})$ & 3.5 & $\omega$ & 0.15 \\
$A(\mathrm{~Pa})$ & 214.4 & $E_{0}\left(\mathrm{~J} / \mathrm{m}^{3}\right)$ & 4.192 \\
$B(\mathrm{~Pa})$ & 0.182 & $V_{0}$ & 1 \\
\hline
\end{tabular}

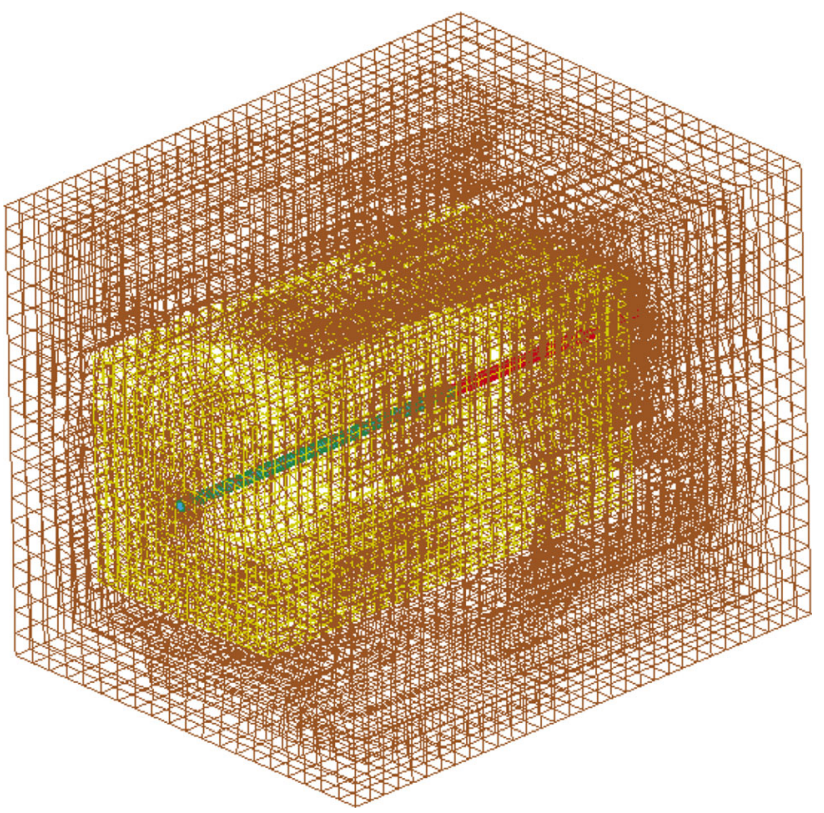

Fig. 4 Established numerical calculation model

process in the drilling hole. The incompressibility and inertial action of the water caused the shock wave to quickly lose energy during propagation in the water medium. The shock wave lasted $300 \mu \mathrm{s}$, and the diameter of the crushed zone around the drilling hole was $20.1 \mathrm{~cm}$. The water medium in the drilling hole slowly decayed the intensity of the shock wave, which entered the surrounding rock of the drilling hole through the water medium. The blasting-induced fracturing has a wide range, and a largescale damage fracture zone is observed around the crushed zone in the surrounding rock of the drilling hole.

During charging, the explosive characteristics and the properties of the surrounding rock remained unchanged. The decoupled material between the explosive and the surrounding rock altered and was set to rock, water, and air. Three models were established for the blasting simulations to investigate the impact of the detonation wave on the hole wall during blasting when full of water and to consider the effects of air-coupling and full-coupling charging conditions.

As shown in Fig. 6, there are different failure duration times and peak intensities of the impact from the detonation wave on the blasting hole under various charging conditions. The detonation wave imposes similar impact and failure actions on the hole wall under coupled and airdecoupled charging conditions. Under full-coupled conditions, the impact of the detonation wave on the hole wall exhibits three peak points at 320,760 and $1600 \mathrm{MPa}$, while only one peak stress point was observed under air-decoupled conditions. The effective stress peaks during blasting with the drilling hole full of water, while air-decoupled 


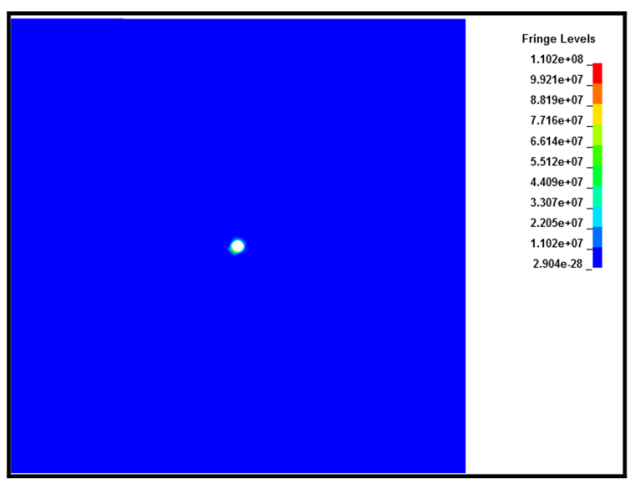

(a) Blasting stage 1

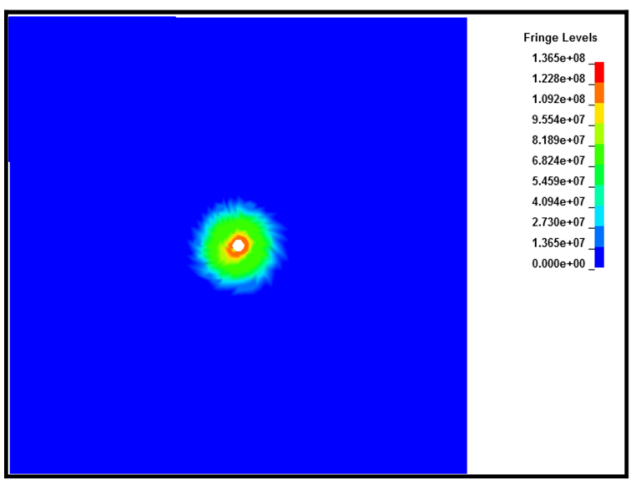

(b) Blasting stage 2

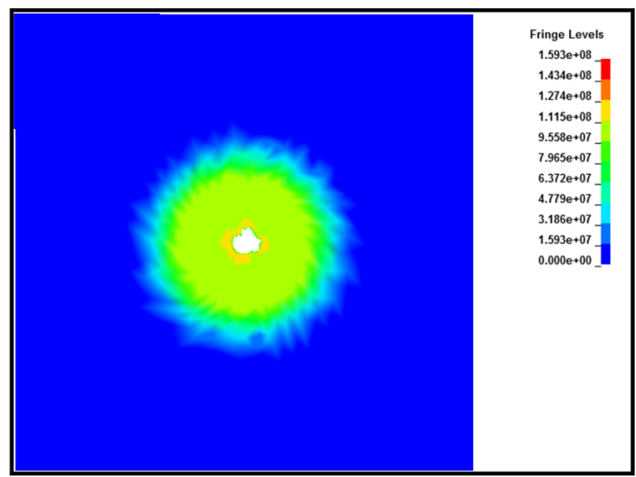

(c) Blasting stage 3

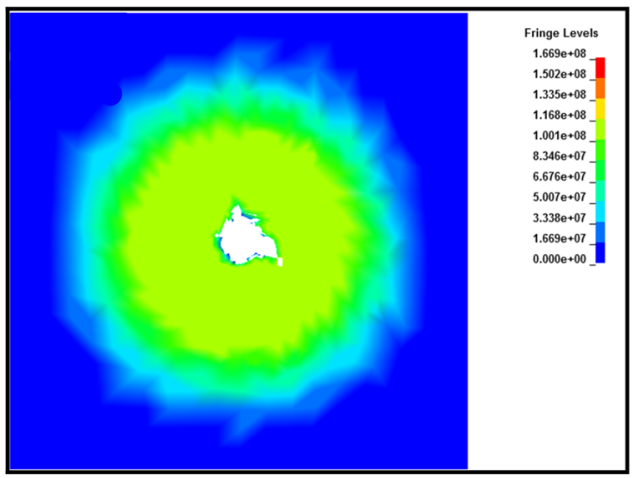

(d) Blasting stage 4
4Fig. 5 Detailed underwater blasting process

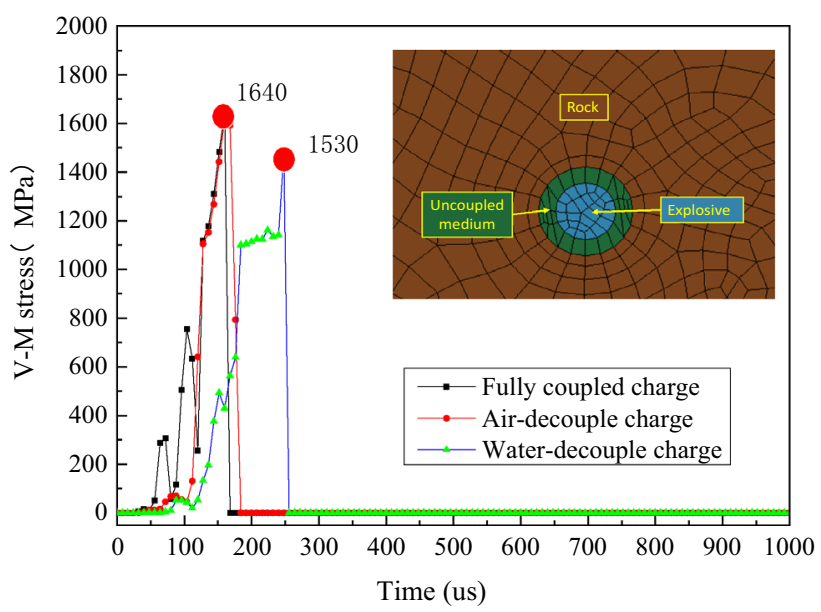

Fig. 6 Impact stresses on the hole wall under different charging conditions

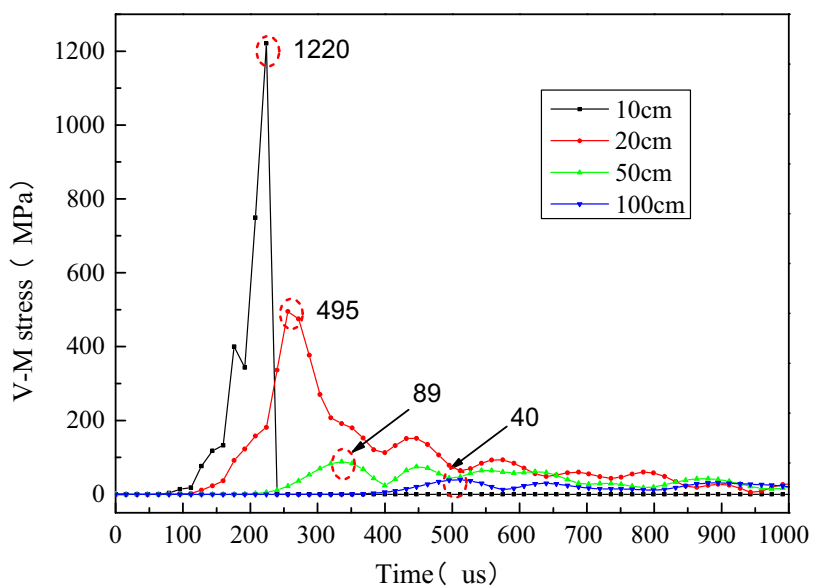

Fig. 7 Time-history curves for effective stress at different positions and distances from blasting hole

detonation conditions are slightly lower at approximately $1530 \mathrm{MPa}$. When the drilling hole is full of water, the detonation wave acts longer and the duration reaches approximately $180 \mu \mathrm{s}$, which is around 50\% longer than under air-decoupled conditions.

Figure 7 shows the relationships between the effective stress and time at $10,20,50$, and $100 \mathrm{~cm}$ from the blasting hole. The node $10 \mathrm{~cm}$ from the blasting hole is closest and located in the crushed zone of the surrounding rock, where the peak intensity of the shock wave approaches $1220 \mathrm{MPa}$. After rock failure, the shock wave exhibits rapid decay. At the observation node $20 \mathrm{~cm}$ from the blasting hole, the peak effective stress is $495 \mathrm{MPa}$, suggesting rock damage. At the observation node $50 \mathrm{~cm}$ from 


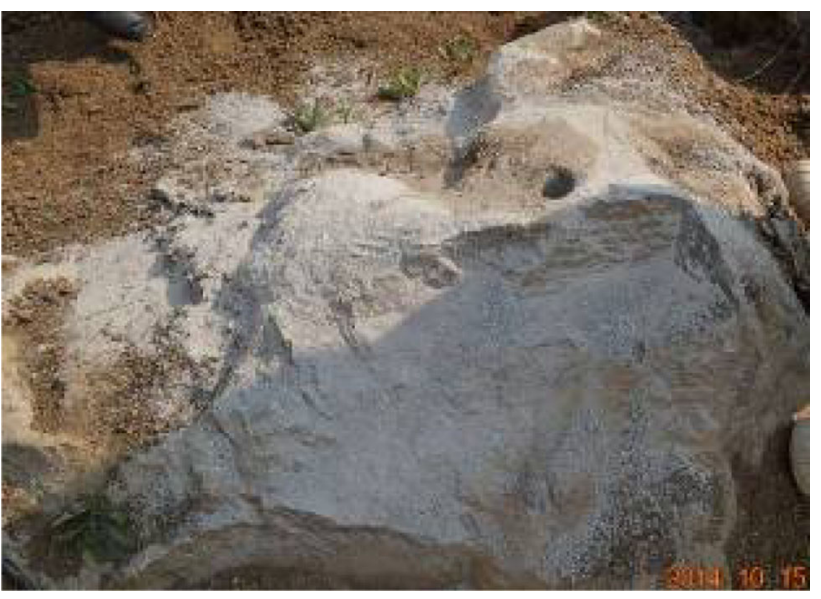

Fig. 8 Natural rock specimen from the quarry

the blasting hole, the peak effective stress on the unit is $89 \mathrm{MPa}$, which may cause certain tensile failure to the rock. At the node $100 \mathrm{~cm}$ from the blasting hole, the peak stress is relatively low as it is far from the center of the blasting hole, suggesting slight damage to the surrounding rock.

To further validate the effectiveness of underwater blasting, a large rock with an appropriate size and regular shape was selected in the quarry as the blasting objective. A drilling pipe with a diameter of $38 \mathrm{~mm}$ was used for drilling. Figure 8 shows a photograph of the natural rock selected in the quarry.

The rock has a buried depth of approximately $3.7 \mathrm{~m}$ and a mean diameter of approximately $1.5 \mathrm{~m}$. The drilling depth is $2.8 \mathrm{~m}$. A total of $10 \mathrm{~g}$ of ammonium nitrate explosive was used for the underwater blasting tests on the rock specimen with a buried depth of $3.7 \mathrm{~m}$. The detailed procedure is described in Fig. 9.

The fractures on the bottom of the hole after the explosion were observed using a borescope. Figure 10 shows the rock damage before and after blasting. The tests demonstrate that using $10 \mathrm{~g}$ of ammonium nitrate explosive can achieve favorable rock breakage performance for large rocks with a volume of approximately $6.5 \mathrm{~m}^{3}$. After underwater blasting, uniform fracturing was realized along the full-length range of the drilling hole. It is therefore concluded that the water medium causes the detonation energy from limited explosive to act uniformly on the fulllength range of the drilling hole, which effectively enhances the energy utilization ratio of the explosive. Therefore, this technique successfully avoids the difficulty of deep-hole charging during underground blasting processes. Thus, relatively little explosive should be placed in the shallow part of the drilling hole.

At the same time, the observation and analysis of the blasting process are used to determine the sound of the rock

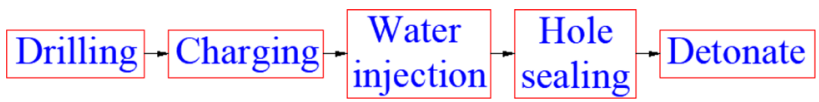

Fig. 9 Procedure for the field test

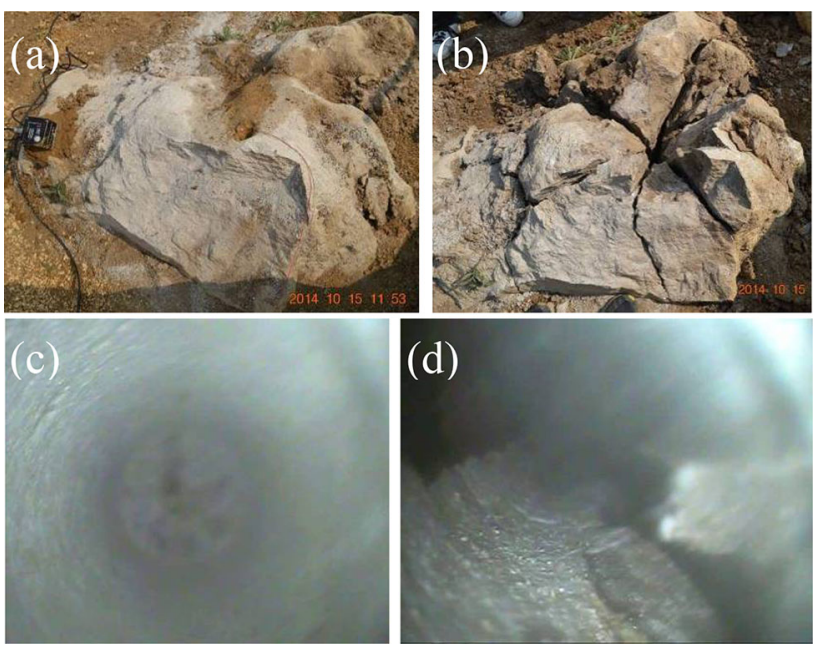

Fig. 10 Rock failure modes before and after underwater blasting: orifice $\mathbf{a}$ before and $\mathbf{b}$ after blasting; hole bottom $\mathbf{c}$ before and $\mathbf{d}$ after blasting

blasting, the intensity of the explosive fire, the amount of rock blasting dust, the rock fragmentation, and the purification time of the gaseous products from detonation in air as the evaluation indexes of the blasting test. The above index evaluation criteria are used to obtain the scores of the rock fracture test results during rock blasting through the independent evaluation of the same test process by multiple individuals, as shown in Table 4.

In Table 4, A represents the charge quantity, B represents the water pressure, and $\mathrm{C}$ represents the charge pipe. The orthogonal test analysis method is used to process the test data and obtain the blasting test results. Table 5 shows that the effect index of the rock blasting test is greatly sensitive to the horizontal water pressure (B). The horizontal charge tube $(\mathrm{C})$, as a secondary sensitive factor, does not significantly affect the rock fracture under the condition of multiple free surfaces. The effect of the charge quantity (A) on the rock blasting index is relatively small, which is not the primary factor for the blasting effect. The best matching combination under these conditions is $\mathrm{B} 2 \mathrm{C} 2 \mathrm{~A} 2$, which uses $3 \mathrm{MPa}$ water as the detonation medium and obtains the best rock fracture effect.

\section{Conclusions}

(1) Underwater blasting exhibits distinct damage zones on the surrounding rock relative to air. The failure mechanism and size of each zone were 
Table 4 Scoring of confined blasting test results

\begin{tabular}{|c|c|c|c|c|c|c|c|}
\hline \multirow{2}{*}{$\begin{array}{l}\text { Combination of } \\
\text { tests }\end{array}$} & \multicolumn{7}{|c|}{ Evaluation score of results } \\
\hline & $\begin{array}{l}\text { Blasting } \\
\text { sound }\end{array}$ & $\begin{array}{l}\text { Explosive fire } \\
\text { intensity }\end{array}$ & $\begin{array}{l}\text { Blasting dust } \\
\text { quantity }\end{array}$ & $\begin{array}{l}\text { Rock } \\
\text { fragmentation }\end{array}$ & $\begin{array}{l}\text { Gaseous purification } \\
\text { time }\end{array}$ & $\begin{array}{l}\text { Total } \\
\text { score }\end{array}$ & $\begin{array}{l}\text { Average } \\
\text { score }\end{array}$ \\
\hline \multirow[t]{3}{*}{$\mathrm{A} 1 \mathrm{~B} 1 \mathrm{C} 1$} & 3 & 2 & 2 & 2 & 1 & 10 & 11.0 \\
\hline & 2 & 1 & 3 & 3 & 2 & 11 & \\
\hline & 3 & 2 & 4 & 2 & 1 & 12 & \\
\hline \multirow[t]{3}{*}{$\mathrm{A} 2 \mathrm{~B} 1 \mathrm{C} 2$} & 4 & 2 & 4 & 1 & 2 & 13 & 14.3 \\
\hline & 5 & 2 & 3 & 2 & 3 & 15 & \\
\hline & 4 & 1 & 5 & 2 & 3 & 15 & \\
\hline \multirow[t]{3}{*}{$\mathrm{A} 2 \mathrm{~B} 2 \mathrm{C} 1$} & 5 & 2 & 5 & 1 & 3 & 16 & 15.7 \\
\hline & 5 & 2 & 4 & 2 & 2 & 15 & \\
\hline & 4 & 2 & 5 & 2 & 3 & 16 & \\
\hline \multirow[t]{3}{*}{$\mathrm{A} 1 \mathrm{~B} 2 \mathrm{C} 2$} & 5 & 2 & 5 & 1 & 3 & 16 & 16.3 \\
\hline & 5 & 2 & 5 & 2 & 3 & 17 & \\
\hline & 5 & 2 & 5 & 1 & 3 & 16 & \\
\hline
\end{tabular}

Table 5 Confined blasting test results

\begin{tabular}{|c|c|c|c|c|}
\hline \multirow[t]{2}{*}{ Number } & \multicolumn{4}{|c|}{ Factor } \\
\hline & A & B & C & Average score \\
\hline 1 & 1 & 1 & 1 & 11.0 \\
\hline 2 & 1 & 2 & 2 & 16.3 \\
\hline 3 & 2 & 1 & 2 & 14.3 \\
\hline 4 & 2 & 2 & 1 & 15.7 \\
\hline I & 27.3 & 25.3 & 26.7 & \\
\hline II & 30.0 & 32.0 & 30.6 & \\
\hline Range & 2.7 & 6.7 & 3.9 & \\
\hline
\end{tabular}

systematically analyzed and solved based on fluid and fracture mechanics to determine the rock breaking mechanism. The rock is first crushed by the shock and stress waves, and the water medium in the hole further expands to promote rock breakage.

(2) The failure radius of the surrounding rock induced from the explosive in the hole is approximately 10-15 times greater than the drilling radius. The fracture-increase model after water medium wedging suggests the water medium should be at a higher initial expansion pressure to achieve fracturing in the surrounding rock when more fractures are present. Given the fixed number of produced fractures, the fracture termination length increases with the initial expansion pressure of the water medium in the hole. Moreover, in surrounding rock with more fractures, the initial expansion pressure of the water in the hole changes slightly.

(3) Both the numerical simulations and field test analysis results show that when the drilling holes are full of water, the blasting duration is long and staticloading rock breakage characteristics can be achieved because of the uniform load-transfer properties. Therefore the static rock breaking effect under a dynamic load can be achieved.

Acknowledgements This work was supported by National Natural Science Foundation of China (51604262), Foundation Research Project of Jiangsu Province (BK20160256), China Postdoctoral Science Foundation Project (2018M632424).

Open Access This article is licensed under a Creative Commons Attribution 4.0 International License, which permits use, sharing, adaptation, distribution and reproduction in any medium or format, as long as you give appropriate credit to the original author(s) and the source, provide a link to the Creative Commons licence, and indicate if changes were made. The images or other third party material in this article are included in the article's Creative Commons licence, unless indicated otherwise in a credit line to the material. If material is not included in the article's Creative Commons licence and your intended use is not permitted by statutory regulation or exceeds the permitted use, you will need to obtain permission directly from the copyright holder. To view a copy of this licence, visit http://creativecommons. org/licenses/by/4.0/.

\section{References}

Cheng XY (2019) Damage and failure characteristics of rock similar materials with pre-existing cracks. Int J Coal Sci Technol 6(4):505-517

Dai J (2001) Calculation of radii of the broken and cracked areas in rock by a long charge explostion. J Liaoning Tech Univ Nat Sci 20(2):144-147

Dai J (2013) Dynamic behaviors and blasting theory of rocks. Metallurgical Industry Press, Beijing

Donze FV, Bouchez J, Magnier SA (1997) Molding fractures in rock blasting. Int J Rock Mech Min Sci 34(8):1153-1163 
Field JE, Pedersen AL (1971) The importance of the reflected stress wave in rock blasting. Int J Rock Mech Min Sci 8(3):213-220

Gao X, Wang HG, Kang XW (2008) Dynamic stress intensity factor and dynamic crack propagation characteristics of anisotropic material. Appl Math Mech 9:1017-1027

Guo J, Cui WQ, Chen H (2016) Numerical analysis of the smooth blasting crack development under different coupling medium. Gold Sci Technol 24(1):68-75

He C, Jun Y (2019) Experimental and numerical investigations of dynamic failure process in rock under blast loading. Tunn Undergr Space Technol 83(1):552-564

Huang B, Li P (2015) Experimental investigation on the basic law of the fracture spatial morphology for water pressure blasting in a drillhole under true triaxial stress. Rock Mech Rock Eng 48(4):1699-1709

Jang H, Handel D, Ko Y, Yang H, Miedecke J (2018) Effects of water deck on rock blasting performance. Int J Rock Mech Min Sci 112:77-83

Kutter HK, Fairhurst C (1971) On the fracture process in blasting. Int J Rock Mech Min Sci 8(3):181-202

Li XB (2011) Drilling and blasting engineering. Central South University, Changsha

Li Q, Yang RS, Li JL (2005) Experimental study on propagation of dynamic cracks under blasting loading. Chin J Rock Mech Eng 24(16):2912-2916

Li L, Yang LP, Cao F, Wang QZ (2016) Complete dynamic fracture process of sandstone under impact loading: experiment and analysis. J China Coal Soc 41(8):1912-1922

Liu CY, Yang JX, Yu B (2017) Rock-breaking mechanism and experimental analysis of confined blasting of borehole surrounding rock. Int J Min Sci Technol 27(5):795-801

Liu RF, Zhu ZM, Liu B, Wan DY, Li M (2019) Experimental study on dynamic fracture characteristics of sandstones under blasting. Chin J Rock Mech Eng 38(3):445-454

Loeber JF, Sih GC (1968) Diffraction of anti-plane shear waves by a finite crack. J Acoust Soc Am 44:711-721
Sih GC, Loeber JF (1969) Wave propagation in an elastic solid with a line of discontinuity or finite crack. Quart Appl Math 27:711-721

Sun JP, Li XJ, Mou YS, Yan HH, Wang XH (2018) Experiment analysis the effect of the initiation form on the rock blasting crack propagation. Eng Blasting 24(3):7-13

Xie Y (2002) The modelling experiment for regularity of blasting crackle spread of rock under high stress conditions. Hunan Nonferr Metal 18(8):1-3

Yang JX (2015) Study on confined blasting control mechanism of hard coal rock with high safety and efficiency and test analysis. Dissertation, Xuzhou China University of Mining and Technology

Yang LY, Ding CX (2018) Fracture mechanism due to blast-imposed loading under high static stress conditions. Int J Rock Mech Min Sci 107:150-158

Yang J, Chen PW, Hu G (2005) Modern blasting technology. Beijing Institute of Technology Press, Beijing

Yang LY, Yang RS, Qu GL et al (2014) Caustic study on blastinduced wing crack behaviors in dynamic-static superimposed stress field. Int Rock Mech Min Sci 24:417-423

Yang R, Yanbing W, Dongming G et al (2016) Experimental research of crack propagation in polymethyl methacrylate material containing flaws under explosive stress waves. J Test Eval 44(1):248-257

Yang R, Chenxi D, Liyun Y et al (2018) Behavior and law of crack propagation in the dynamic-static superimposed stress field. J Test Eval 46(6):2540-2548

Zhang Q (1990) Smash districts and expanding of cavities in rock blasting. Explos Shock Waves 10(1):68-75

Zhang ZX (2002) An empirical relation between mode I fracture toughness and the tensile strength of rock. Int J Rock Mech Min Sci 3:401-406

Zuo JP, Wang JT, Jiang YQ (2019) Macro/meso failure behavior of surrounding rock in deep roadway and its control technology. Int J Coal Sci Technol 6(3):301-319 